\title{
A Minuscule Appraise on the Outcome of BI and SB Metallic Additives on Refining the Microstructure and Mechanical Behavior of few Magnesium Alloys
}

\author{
Vignesh Sreekandan Nair, Jothiraj Palaniappan, Winowlin Jappes J T
}

\begin{abstract}
This paper reviews the outcome of bismuth and antimony trappings on the microstructure and mechanical behavior of an assortment of commercial magnesium alloys. Various compositions of the Bi and $\mathrm{Sb}$ were discussed along with/without combination of other alloying elements. These additions have revealed to be resulted in the formation of $\mathrm{Mg}_{3} \mathrm{Bi}_{2}$, $\mathrm{Mg}_{3} \mathrm{Sb}_{2}$ intermediate phases when added upon with corresponding alloying elements. Moreover the reasons for the observed changes due to the addition of these alloying elements were also reviewed. It is found that the accumulation of Bi phase as well as intermetallics and $S b$ intermediates has greatly improved the microstructure belonging to the as cast magnesium alloys thereby improving both mechanical and thermo-mechanical properties. It is also observed in the review that addition of thesealloying elements acted as grain refiner and improved the corrosion resistance of commercial magnesium alloys.
\end{abstract}

Keywords : Antimony, Bismuth, Grain refinement, Magnesium Alloys, Mechanical Properties.

\section{INTRODUCTION}

Weight reduction nowadays being a primary objective of almost all technologists, particularly in automotive applications, aerospace applications, portable microelectronics and telecommunication has induced them to look for greater and low density structural materials [1-8]. Magnesium, possessing $1.74 \mathrm{~g} / \mathrm{cm} 3$ is one of the lightest structural materials and is steel. The research and development of magnesium alloys has been greatly promoted owing to their good machinability, low density, good thermal conductivity, high specific strength, high stiffness ratio, and good damping capability and for these reasons magnesium alloys have been called "the 21th century engineering materials"[9]. The $\mathrm{Mg}$ alloy combinations as an outcome of

Revised Manuscript Received on December 5, 2019

* Correspondence Author

Vignesh Sreekandan Nair*, Department of Mechanical Engineering, Kalasalingam, Academy of Research and Education, Krishnankoil, India, vignesh@klu.ac.in

Jothiraj Palaniappan, Department of Mechanical Engineering, Kalasalingam, Academy of Research and Education, Krishnankoil, India, jothiraj@klu.ac.in

Winowlin Jappes JT, Department of Mechanical Engineering, Kalasalingam, Academy of Research and Education, Krishnankoil, India, winowlin@klu.ac.in

smorgasbord of additives end up with great potential in reducing the weight of the product thereby enhancing the automotive to greatly reduce the fuel consumption which allows the vehicle to emit reduced harmful agents. Hence to achieve this, replacement of $\mathrm{Al}$ and $\mathrm{Fe}$ based alloys with $\mathrm{Mg}$ can be done to offer a low- cost solution. Magnesium alloys when classified will subdivide into the ones which can be produced as an outcome of melting and solidification and another one as product of hammering resulting to which desired shape is obtained. Main commercial $\mathrm{Mg}$ alloys include the AZ31, AZ91, AM50 and AM60[11]. The most usual magnesium alloys based on $\mathrm{Mg}$ - Aluminium arrangement due to their excellent room temperature strength, casting properties and low cost. However these alloy lack in yield strength, elevated temperature properties and also drastic reduction in tensile and creep properties beyond $125^{\circ} \mathrm{C}$ because of the coarsening of boundaries and intermetallic regions of $\mathrm{Mg}_{17} \mathrm{Al}_{12}$ secondary phase in the $\mathrm{Mg}$-Al systems. This is mainly credited due to the lower melting point of $\mathrm{Mg}_{17} \mathrm{Al}_{12}$ revealed $30 \%$ lighter than $\mathrm{Al}$ alloys and $70 \%$ lighter than that of phase and the $\mathrm{Al}$ possessing diffusivity being excellent in $\mathrm{Mg}$ matrix which results in unsuitability of using commercial AZ alloys for the extreme mechanical applications including the sections like block of the engine, cases cover the crank and transmission gear boxes which are forced to undergo elevated temperature[12]. It is therefore essential to develop magnesium alloys which are non-affinity towards creep for power train modules in automobiles as well as in aerospace applications which is responsible not only for weight reduction but also for opting the alloy for enhanced molecular momentum of the material resulting in in situ creep resisting alloys.

\section{MICROSTRUCTURE OF MAGNESIUM ALLOYS}

$\mathrm{H}$ Pan et al, has investigated the changes in the morphologies pertaining to the structure and the corresponding mechanical behavior of the alloy and reported positive changes in the structural morphology and also reported the detrimental performance of $\mathrm{AZ}$ in its mechanical behavior such as tensile strength and ductility as well[13]. Wide mixtures of composition of antimony added were reported in the Table-I below. 
A Minuscule Appraise on the Outcome of BI and SB Metallic Additives on Refining the Microstructure and Mechanical Behavior of few Magnesium Alloys

Table-I: Composition of the as-prepared samples

\begin{tabular}{|c|c|}
\hline Sample & Composition \\
\hline 1 & AZ31 \\
\hline 2 & AZ31-0.3Sb \\
\hline 3 & AZ31-0.45Sb \\
\hline 4 & AZ31-0.6Sb \\
\hline
\end{tabular}

AZ31 as a result of the morphological analysis as reported by the researchers comprised of a mono phase hexagonally closed packed $\alpha$ - Mg and the sample as-prepared augmented with the metallic particles of antimony gave result to di-phased $\alpha-\mathrm{Mg}$ and $\alpha-\mathrm{Mg}_{3} \mathrm{Sb}_{2}$ intermediate compound which war reported to be discovered from the XRD analysis. The volumetric fractions calculated from the XRD increased with increasing addition of $\mathrm{Sb}$ which was found to be obvious. The structure bared from optical analysis of AZ31 augmented with antimony had shown different phases comprising of grains equiaxed comprising $\alpha-\mathrm{Mg}$ with a greater size of grains and precipitates of rod shaped $\alpha-\mathrm{Mg}_{3} \mathrm{Sb}_{2}$ which are concluded as the thermally consistent intermetallic phase with enhanced melting point, found to have precisely homogenous and distributed consistently in matrix as well, which was also expressively unlike from that of AZ31. The microstructure obtained by the researchers clearly depicted the equally centered single phase $\alpha-\mathrm{Mg}$

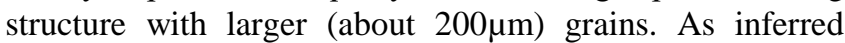
earlier addition of $\mathrm{Sb}$ resulted in the formation of bigger grains and precipitates of rod like structure which are found distributed at the boundaries of the grains and disseminated in the interior of the grains homogeneously.

There are two major scientific observations behind the growth of rod like structured precipitates of $\alpha-\mathrm{Mg}_{3} \mathrm{Sb}_{2}$ is that affinity between Magnesium and antimony is brawny, which is due to the electro negativity difference. The homogeneous distribution was due to the following which is in accordance with the $\mathrm{W}$ Zhou et al..[14] i.e. the growth of nucleation and the nucleation sites of $\alpha-\mathrm{Mg}_{3} \mathrm{Sb}_{2}$ and $\alpha-\mathrm{Mg}$ are separated from pouring owing to the mold wall separation from the filters. Hence from the above we can infer that the homogenous nucleation is obtained upon detaching the walls of molding from the filters when pouring.

Also one can infer from the work suggested by the above researcher that the nucleation of both $\alpha-\mathrm{Mg}_{3} \mathrm{Sb}_{2}$ and $\alpha-\mathrm{Mg}$ tends to glorify without hindering the growth of each one another. On the other hand, it is clear and evident from the work that $\alpha$ - Mg not only buds upon nucleation but also begin to swallow $\alpha-\mathrm{Mg}_{3} \mathrm{Sb}_{2}$ thereby glorify itself to attain the uniform distribution along the grains[15].

\section{MECHANICAL PROPERTIES}

After the addition of Sb to AZ31 it is inferred that the tensile strength was decreased to $175.7 \mathrm{MPa}(0.6 \mathrm{wt} \% \mathrm{Sb})$ from $201.17 \mathrm{MPa}$ (without $\mathrm{Sb}$ ) resulting in the reduction of $12.6 \%$ Similarly it is observed that the elongation has been reduced from $17.16 \%$ (without $\mathrm{Sb}$ ) to $11.58 \%(0.6 \mathrm{wt} \% \mathrm{Sb}$ ) which resulted in $32.5 \%$ reduction. The reason behind this reduction in the mechanical properties was reported as earlier as a cause of the microstructural morphology which comprises of the precipitate of rod like structure which in turn concentrates more stress on itself upon subjecting to the mechanical conditions. The failure mode of AZ31 alloy with and without addition of $\mathrm{Sb}$ was reported to be brittle intergranular failure.

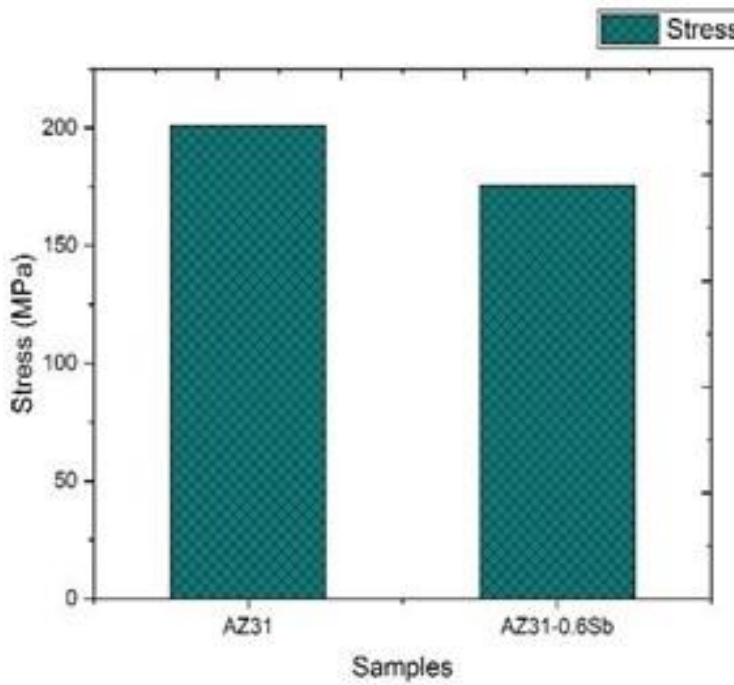

Fig.1. Mechanical Properties of the AZ Alloy when augmented with antimony

Some researchers investigated the effect of $\mathrm{Sb}$ augmentation on the microstructure and tensile behavior of AZ64 Mg alloy. The research team portrayed the morphologies of the aforementioned alloys with and without metallic additives of antimony to AZ64. It can be inferred from the microstructure that the refinement of secondary phases of AZ64 was achieved solely by augmenting antimony. In as cast AZ64, the secondary phases were broadened along the boundaries of the grain thereby making an agglomeration within the grains whereas the antimony additives were reported to cause the inferior phases to spread on the vicinity of the boundaries and also were found to be refined to the core[16-17].

The XRD analysis examined by the team revealed the main secondary phases of as- cast AZ64 and AZ64- 0.5 wt \% Sb alloys as $\gamma-\mathrm{Mg}_{12}(\mathrm{Al}, \mathrm{Zn})_{17}$ phase and $\pi-\mathrm{Mg}_{21}(\mathrm{Zn}, \mathrm{Al})_{17}$ phase. It can be inferred from the figure that the dark and bright secondary phases are located as $\gamma-\operatorname{Mg}_{12}(\mathrm{Al}, \mathrm{Zn})_{17}$ phase and $\pi-\mathrm{Mg}_{21}(\mathrm{Zn}, \quad \mathrm{Al})_{17}$ respectively as the $\gamma-\operatorname{Mg}_{12}(\mathrm{Al}, \mathrm{Zn})_{17}$ contains reduced composition of zinc however than $\pi-\mathrm{Mg}_{21}(\mathrm{Zn}, \mathrm{Al})_{17}$ which was resulted from EDX. It was also inferred from the micro structural results that the resulting formation of $\mathrm{Mg}_{3} \mathrm{Sb}_{2}$ phase was due to the addition of antimony. Moreover antimony has contributed in the grain refinement because of its very low (almost zero) solubility in magnesium. It is also reported that owing to reduced solubility of the additives, undercooling of the melt is resulted in the diffusion layer when solidification at the interface. Grain growth theory, according to which the agglomerated $\mathrm{Sb}$ would hinder the superior growth of grains thereby damming the growth of the crystal and this may be the reason for the addition of antimony as carbon inoculation agent with magnesite particles. 
The researchers reported the microstructure of refined grains of AZ64 when added with Carbon acted as carbon immunization. Furthermore it was clear from the work that temper heat treatment $\mathrm{T} 6$ process enhanced the mechanical muscularity of the material. However the after testing of materials for microstructure revealed the transformations of grains from coarser into finer grains owing to the carbon immunization technique which is intrinsically evolved and were characterized as $\mathrm{Mg}_{3} \mathrm{Sb}_{2}$ and/or Al- Mn phases [18-19].

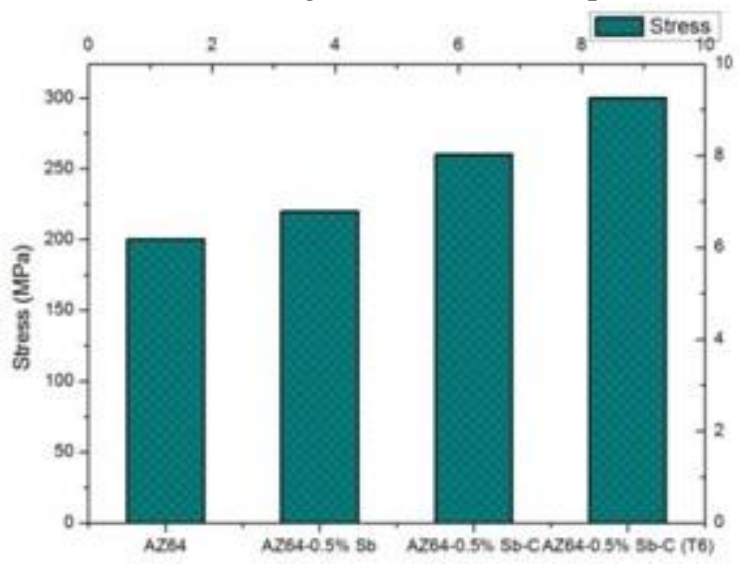

Fig.2. The effects of Immunization with Carbon and addition of Antimony in Tensile Behavior

The tensile results which is as shown in figure depicts the improvement in the mechanical behavior of commercial AZ alloy after the addition of antimony. It can be also inferred that further tensile strength improvement might be due to carbon vaccination with magnesite. The maximum tensile properties of alloys were reported to be observed after T6 treatment which were $\mathrm{YTS}=158 \mathrm{MPa}, \mathrm{UTS}=308 \mathrm{MPa}$ and elongation of $7.0 \%$ which is comparatively higher than that of AZ91 magnesium alloy. The improvement in tensile strength of the same was suggested to be greatly attributed by the strengthening mechanism which involves intrinsically within the material upon subjecting to the loading. On the other hand it was also reported that dispersion strengthening as a result of grain refining was also suggested as the key to improve the mechanical behavior of the alloy when subjected to the extreme mechanical conditions.

F Wang et al has studied the effects of additions of bismuth and antimony on the structural, morphological and mechanical behavior of the commercial magnesium AZ91 alloy and reported the presence $\alpha-\mathrm{Mg}$ (matrix) and $\beta\left(\mathrm{Mg}_{17} \mathrm{Al}_{12}\right)$ grains, and were found to be mainly agglomerated at grain boundaries that can be inferred from his works. Moreover the microstructure was reported to have an improved appearance of the $\beta$-phases more than that of the as solidified alloy. On the other hand, few needle like grains were found to be distributed along the grains and also found to have augmented and agglomerated along the grain boundaries as well, were identified as $\mathrm{Mg}_{3} \mathrm{Bi}_{2}$ phase conformed with respect of the micro analysis[20].

The synonymous microstructure was reported to be observed by the researcher in the material augmented with $\mathrm{Sb}$ and was stated due to the intermetallics of $\mathrm{Sb}$ is alike in structure that of $\mathrm{Mg}_{3} \mathrm{Bi}_{2}$. The augmented addition of bismuth and antimony had both $\mathrm{Mg}_{3} \mathrm{Bi}_{2}$ and $\mathrm{Mg}_{3} \mathrm{Sb}_{2}$ phases which was ascribed from the works suggested. Moreover the $\beta$ precipitates of the material as cast exhibited in-situ finer grains those are much more uniformly spread across than that in the base alloy under study. Further it is revealed that the solution treatment which is a heat treatment phenomenon followed for the material under study did not influence positively on the dissolution of the intermediate particles thereby confirming the consistency of the same under elevated temperatures. As a result of solution treatment, it was suggested that $\beta\left(\mathrm{Mg}_{17} \mathrm{Al}_{12}\right)$ approximately all the same had dissolute. The outcome of minor addition of $\mathrm{Bi}$ and $\mathrm{Sb}$ which seems to be important in suppressing the discontinuous precipitation of $\mathrm{Mg}_{17} \mathrm{Al}_{12}$ and the same was confirmed by the authors through microstructure. It was stated that the ageing of alloy $\mathrm{n}$ a predetermined temperature resulted in the generation of $\mathrm{Mg}_{17} \mathrm{Al}_{12}$ precipitates and the same occurred predominantly in two forms namely discontinuous and continuous precipitation which was proposed by $\mathrm{F}$ Wang. The work also suggested that the superior behavior in terms of agglomeration of discontinuous precipitation in the locality of boundaries of grains which was confirmed from the microstructures of the aged specimen of AZ91 and was attributed due to the absence of $\mathrm{Bi}$ and $\mathrm{Sb}$ while the addition of bismuth and antimony greatly suppressed the discontinuous precipitation which gave way to the observation of few fine continuous plate- shaped precipitates at boundaries that can be inferred from the work by these researchers.

\section{CONCLUSION}

This present article appraises the effect of the minor metallic additions like antimony and bismuth with some commercial magnesium alloys and the changes in the microstructure and evolution in the microstructure is criticized as well. Along with the above, the mechanical properties of the material were also appraised when added with these minor alloying elements. The critique reveals the superior performance of magnesium alloy when added with bismuth in small concentration with respect to the microstructural evolution. The grain refinement was observed and homogenous grain distribution along the boundaries was also reported by a few technologists. However some commercial magnesium alloys exhibited reduction in mechanical properties owing to the addition of antimony in small concentration.

\section{REFERENCES}

1. W. Zhou, N. N. Aung, and Y. Sun, "Effect of antimony, bismuth and calcium addition on corrosion and electrochemical behaviour of AZ91 magnesium alloy," Corros. Sci., vol. 51, no. 2, pp. 403-408, Feb. 2009

2. [M. Keyvani, R. Mahmudi, and G. Nayyeri, "Effect of Bi, Sb, and Ca additions on the hot hardness and microstructure of cast Mg-5Sn alloy,' Mater. Sci. Eng. A, vol. 527, no. 29-30, pp. 7714-7718, Nov. 2010.

3. Z. Jiang, B. Jiang, H. Yang, Q. Yang, J. Dai, and F. Pan, "Influence of the $\mathrm{Al} 2 \mathrm{Ca}$ phase on microstructure and mechanical properties of Mg-Al-Ca alloys,” J. Alloys Compd., vol. 647, pp. 357-363, Jul. 2015.

4. X. Fang, M. Song, K. Li, and Y. Du, "Precipitation sequence of an aged Al-Mg-Si alloy," J. Min. Metall. Sect. B Metall., vol. 46, no. 2, pp. $171-180,2010$. 


\section{A Minuscule Appraise on the Outcome of BI and SB Metallic Additives on Refining the Microstructure and Mechanical Behavior of few Magnesium Alloys}

5. F. Habashi, "Recent trends in extractive metallurgy," J. Min. Metall. Sect. B Metall., vol. 45, no. 1, pp. 1-13, 2009.

6. R. Padilla, L. C. Chambi, and M. C. Ruiz, "Antimony production by carbothermic reduction of stibnite in the presence of lime," J. Min. Metall. Sect. B Metall., vol. 50, no. 1, pp. 5-13, 2014.

7. W. Gierlotka, "A new thermodynamic description of the binary $\mathrm{Sb}-\mathrm{Zn}$ system," J. Min. Metall. Sect. B Metall., vol. 50, no. 2, pp. 149-155, 2014.

8. F. Zhang, Y. Tang, B. Hu, S. Liu, Y. Du, and Y. Zhang, "Thermodynamic assessment of the mg-pb and mg-bi systems using substitutional solution and associate models for the liquid phase," J. Min. Metall. Sect. B Metall., vol. 50, no. 2, pp. 115-126, 2014.

9. A. A. Bryukhanov et al., "Anisotropy of mechanical properties of magnesium alloy AZ31 sheets as a result of sign-variable bending deformation," Metall. Min. Ind., vol. 2, no. 3, pp. 215-219, 2010.

10. Z. Li, Q. Wang, A. A. Luo, L. Peng, and P. Zhang, "Fatigue behavior and life prediction of cast magnesium alloys," Mater. Sci. Eng. A, vol. 647, pp. 113-126, Oct. 2015.

11. L. Ceschini, A. Morri, S. Toschi, and S. Seifeddine, "Room and high temperature fatigue behaviour of the A354 and C355 (Al-Si-Cu-Mg) alloys: Role of microstructure and heat treatment," Mater. Sci. Eng. A, vol. 653 , pp. 129-138, Jan. 2016.

12. R. A. Antunes and M. C. L. de Oliveira, "Effect of surface treatments on the fatigue life of magnesium and its alloys for biomedical applications," in Surface Modification of Magnesium and its Alloys for Biomedical Applications, vol. 1, Elsevier Ltd, 2015, pp. 283-310.

13. H. Pan et al., "Recent developments in rare-earth free wrought magnesium alloys having high strength: A review," Journal of Alloys and Compounds, vol. 663. Elsevier Ltd, pp. 321-331, 05-Apr-2016.

14. W. Zhou, N. N. Aung, and Y. Sun, "Effect of antimony, bismuth and calcium addition on corrosion and electrochemical behaviour of AZ91 magnesium alloy," Corros. Sci., vol. 51, no. 2, pp. 403-408, Feb. 2009.

15. J. Wang, H. Qi, H. Zhu, S. Guan, X. Yu, and Y. Fan, "A study of the effect of antimony content on damping capacity of ZA84 magnesium alloy," Mater. Des., vol. 32, no. 8-9, pp. 4567-4572, Sep. 2011.

16. R. Alizadeh and R. Mahmudi, "Evaluating high-temperature mechanical behavior of cast $\mathrm{Mg}-4 \mathrm{Zn}-\mathrm{xSb}$ magnesium alloys by shear punch testing," Mater. Sci. Eng. A, vol. 527, no. 16-17, pp. 3975-3983, Jun. 2010

17. Q. Wang, Y. Zhu, W. Chen, W. Ding, and M. Mabuchi, "Effect of Sb on the microstructure and mechanical properties of AZ91 magnesium alloy," Metall. Mater. Trans. A, vol. 32, no. 3, pp. 787-794, Apr. 2007.

18. R. CHENG, F. PAN, M. YANG, and A. TANG, "Effects of various $\mathrm{Mg}-\mathrm{Sr}$ master alloys on microstructural refinement of ZK60 magnesium alloy," Trans. Nonferrous Met. Soc. China, vol. 18, pp. s50-s54, Jun. 2010

19. E. Levent, Z. Huseyin, T. Yunus, T. Muhammet Emre, S. Yavuz, and A. Hayrettin, "EFFECTS OF BISMUTH (BI) ADDITIONS ON MICROSTRUCTURE AND MECHANICAL PROPERTIES OF AZ91 ALLOY."

20. F. Wang, J. Li, J. Liu, P. Mao, and Z. Liu, "The Influence of Ca and Y on the Microstructure and Corrosion Resistance of Vacuum Die Casting AZ91 Alloy."

\section{AUTHORS PROFILE}

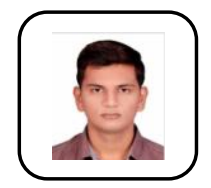

Vignesh Sreekandan Nair has graduated in the field of Mechanical Engineering from Anna University in 2013. $\mathrm{He}$ completed his post-graduation in Manufacturing Engineering from Anna University in 2016. He has published one paper in peer reviewed journal. His research area of interests are casting of non-ferrous alloys, development of polymer composites and mechanical behavior of materials. Presently he is working with Kalasalingam Academy of Research and Education as an Assistant professor in the department of Mechanical Engineering.

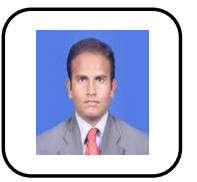

Jothiraj Palaniappanhas completed his bachelor's degree in the department of Mechanical Engineering under Anna University with First rank and gold medal, proceeded with the degree of masters under the Manufacturing Engineering with First Rank and Gold medal. He is being nominated and selected as the Mentor for change under the NITI-Ayog, Govt. of India for AIM. Has published two papers in peer reviewed journals. Active member in the IAEng. Research interest being inclined towards the advanced materials as shape memory alloys and phase changing materials

Winowlin Jappes $\mathbf{J} \quad \mathbf{T}$ graduated in 1997 from Manonmaniam Sunderanar University, India in Mechanical Engineering. In 1999, he has completed his masters in Production Engineering from Annamalai University. He completed his Ph.D degree in 2004 in the area of Composite Deposition at Indian Institute of Technology Madras, Chennai. He has completed three DST funded research projects and published more than 125 research articles which includes 65 International Journal papers. Currently, he is working as Senior Professor in Kalasalingam University, India. His research interests includes high performance composite materials, machining of hard materials, optimization techniques, etc. At present, he is working as Professor and Dean, School of Automotive and Mechanical Engineering, Kalasalingam Academy of Research and Education, India. 